\title{
Molecular and cellular characterization during chondro- genic differentiation of adipose tissue-derived stromal cells in vitro and cartilage formation in vivo
}

\author{
Yunfeng Lin a, En Luo ${ }^{a}$, Xizhe Chen a, Lei Liu ${ }^{a}$, Ju Qiao ${ }^{b}$, Zhengbin Yan a, \\ Zhiyong Lia ${ }^{a}$ Wei Tang a, Xiaohui Zhenga, Weidong Tian a * \\ a Department of Oral and Maxillofacial Surgery, West China College of Stomatology, \\ Sichuan University, Chengdu, P. R. China \\ ${ }^{b}$ Department of Orthodontics, West China College of Stomatology, Sichuan University, \\ Chengdu, P. R. China
}

Received: April 25, 2005; Accepted: October 7, 2005

\begin{abstract}
Human adipose tissue is a viable source of mesenchymal stem cells (MSCs) with wide differentiation potential for musculoskeletal tissue engineering research. The stem cell population, termed processed lipoaspirate (PLA) cells, can be isolated from human lipoaspirates and expanded in vitro easily. This study was to determine molecular and cellular characterization of PLA cells during chondrogenic differentiation in vitro and cartilage formation in vivo. When cultured in vitro with chondrogenic medium as monolayers in high density, they could be induced toward the chondrogenic lineages. To determine their ability of cartilage formation in vivo, the induced cells in alginate gel were implanted in nude mice subcutaneously for up to 20 weeks. Histological and immunohistochemical analysis of the induced cells and retrieved specimens from nude mice at various intervals showed obviously cartilaginous phenotype with positive staining of specific extracellular matrix (ECM). Correlatively, results of RT-PCR and Western Blot confirmed the expression of characteristic molecules during chondrogenic differentiation namely collagen type II, SOX9, cartilage oligomeric protein (COMP) and the cartilage-specific proteoglycan aggrecan. Meanwhile, there was low level synthesis of collagen type $\mathrm{X}$ and decreasing production of collagen type I during induction in vitro and formation of cartilaginous tissue in vivo. These cells induced to form engineered cartilage can maintain the stable phenotype and indicate no sign of hypertrophy in 20 weeks in vivo, however, when they cultured as monolayers, they showed prehypertrophic alteration in late stage about 10 weeks after induction. Therefore, it is suggested that human adipose tissue may represent a novel plentiful source of multipotential stem cells capable of undergoing chondrogenesis and forming engineered cartilage.
\end{abstract}

Keywords: chondrogenic differentiation - lipoaspirate cells • collagen • cartilage oligomeric protein

\section{Introduction}

Damaged or degenerative cartilage has a limited potential for repair, and hence large defects never

* Correspondence to: Weidong TIAN

Department of Oral and Maxillofacial Surgery,

West China College of Stomatology, Sichuan University,

Chengdu 610041, P.R.China.

Tel.:86-028-85503406

E-mail: dentisttian@hotmail.com heal spontaneously, which causes the primary complaint of orthopedic patients. Till now, the repair of articular cartilage lesions remains a significant clinical challenge. Conventional treatments do not result in complete regeneration of the original hyaline architecture. Thereby, the diseased joint always loses normal flexibility for weight-bearing and physical activity in prolonged 
periods [1]. Autogenous osteochondral grafts or chondrocytes transplantation appear to be efficacious, but they require an invasive protocol and suffer from size constraints, donor site morbidity, and senescence during cell culture in vitro [2]. It is clearly important to identify other sources of chondrocytic precursors, and mesenchymal stem cell reserves in various sites may represent a promising pool of candidate cells for the engineered repair and regeneration of tissues and organ systems [3].

Stem cells possess self-renewal, long-term cell viability, and multilineage differentiation potential, all of which make them taken as the best seed cells. However, application of multipotent embryonic stem cells may be restricted because of ethical issues and problems on the regulation of cell differentiation in vivo. Furthermore, to avoid possible immunological complications from a xenograft, it is considered that adult stem cells are a more logical population for engineered tissue. Bone marrow stem cells (BMSCs) have excellent capacity to proliferate in culture and differentiate into a wide variety of cell types in response to appropriate culture system [4]. Unfortunately, it remains concerned about the discomfort and pain associated with bone marrow procurement, low cell number upon harvest, and heterogeneous nature of BMSC population which shows a broad range of colony size, varying growth rates and different cell morphologies, ranging from fibroblast-like spindle shaped cells to large flat cells. The heterogeneity of BMSCs with both hemopoietic and mesenchymal stem cells confounds the result of various therapies using bone marrow $[5,6]$.

Recently, it has been reported that human adipose tissue-derived stromal cells can be induced to express genes and matrix markers associated with the adipocyte, osteoblast, chondrocyte and myocyte pathways using specific culture conditions [7-9]. Adipose tissue, like bone marrow, is derived from the embryonic mesenchyme and contains a stroma that is easily isolated. Processed Lipoaspirate (PLA) cells are available in large quantities with minimal possibility of morbidity and discomfort clinically. In view of these practical advantages, PLA cells are an alternative for chondrocytes or BMSCs used in research of engineered cartilage.
The embryonic stem cells and adult stem cells from the bone marrow have been characterized extensively. But there is no detailed description of physiological process when PLA cells are undergoing chondrogenic differentiation. [10, 11]. Based on the previous studies that PLA cells can synthesize cartilage extracellular matrix in controlled conditions, this study attempted to investigate the molecular and cellular events in PLA cells during chondrogenesis in vitro and cartilage formation in vivo. Firstly, we aimed to provide mechanistic information on how the adiposederived strains are induced to chondrogenic phenotype. More important to us was the development and maturity of the cartilage formed by these induced PLA cells. With use of alginate scaffold for in vivo implantation, it was to determine how stable the engineered tissue was, and whether it would turn to hypertrophic cartilage. Based on the results of this study, we can better harness the beneficial properties of PLA cells for biotechnology of cartilage engineering.

\section{Materials and methods}

\section{Isolation and culture of PLA cells}

Human adipose tissue was obtained from 9 healthy donors (age range, 25 to 35 years) during the liposuction procedure under local anesthesia. All procedures were approved by the Human Subject Protection Committee (Protocol HSPC 98-08-011-01). Raw lipoaspirates (about $40 \mathrm{ml}$ ) were washed extensively with sterile phosphate-buffered saline (PBS) to remove contaminating debris and red blood cells. To remove adherent ECM, adipose specimens were incubated with $0.075 \%$ type I collagenase (Sigma-Aldrich, St. Louis, MO) in PBS for $60 \mathrm{~min}$ at $37^{\circ} \mathrm{C}$ with gentle agitation. Cells released by the enzymatic digestion were filtered and collected by centrifugation at $1200 \mathrm{~g}$ for 10 minutes. Then, the pellet was resuspended, washed 3 times with medium, and seeded on the plastic tissue culture dishes in control medium containing DMEM/F12 (1:1), 10\% fetal bovine serum (FBS), 100 units $/ \mathrm{ml}$ penicillin, and $100 \mu \mathrm{g} / \mathrm{ml}$ streptomycin [12, 13]. PLA Cells were maintained in a humidified atmosphere of $5 \% \mathrm{CO}_{2}$ at $37^{\circ} \mathrm{C}$ and passaged 3 times prior to chondrogenic differentiation. 
Table 1. Specific primers for PCR amplication listed with expected fragments size and optimal annealing temperature

\begin{tabular}{|c|c|c|c|c|c|}
\hline Gene & Primers & $\begin{array}{c}\text { Annealing } \\
\text { Temperature } \\
\left({ }^{\circ} \mathrm{C}\right)\end{array}$ & $\begin{array}{l}\text { Fragment } \\
\text { (bp) }\end{array}$ & $\begin{array}{l}\text { Cycle } \\
\text { No. }\end{array}$ & $\begin{array}{c}\text { GenBank } \\
\text { No. }\end{array}$ \\
\hline$\beta$-actin & $\begin{array}{l}\text { 5'- ACTCTTCCAGCCTTCCTTCC-3' } \\
\text { 5'- ACTCGTCATACTCCTGCTTGC-3' }\end{array}$ & 55 & 313 & 30 & $\mathrm{BC} 013835$ \\
\hline SOX9 & $\begin{array}{l}\text { 5'-GAACGCACATCAAGACGGAG-3' } \\
\text { 5'-TCTCGTTGATTTCGCTGCTC-3' }\end{array}$ & 60 & 631 & 28 & NM_000346 \\
\hline Aggrecan & $\begin{array}{l}\text { 5'-GCAGAGACGCATCTAGAAATTG-3' } \\
\text { 5'-GGTAATTGCAGGGAACATCATT-3' }\end{array}$ & 55 & 504 & 31 & NM_013227 \\
\hline $\begin{array}{c}\text { Link } \\
\text { Protein }\end{array}$ & $\begin{array}{l}\text { 5'-CCTATGATGAAGCGGTGC-3' } \\
\text { 5'-TTGTGCTTGTGGAACCTG-3' }\end{array}$ & 56 & 618 & 33 & NM_001884 \\
\hline Col-I & $\begin{array}{l}\text { 5'-CATCTCCCCTTCGTTTTTGA-3' } \\
\text { 5'-CTGTGGAGGAGGGTTTCAGA-3' }\end{array}$ & 62 & 598 & 30 & NM_000088 \\
\hline Col-II & $\begin{array}{l}\text { 5'-TTCAGCTATGGAGATGACAATC-3' } \\
\text { 5'-AGAGTCCTAGAGTGACTGAG-3' }\end{array}$ & 55 & 472 & 31 & BC007252 \\
\hline Col-X & $\begin{array}{l}\text { 5'-CACCAGGCATTCCAGGATTCC-3' } \\
\text { 5'-AGGTTTGTTGGTCTGATAGCTC-3' }\end{array}$ & 55 & 825 & 32 & NM_000493 \\
\hline COMP & $\begin{array}{l}\text { 5'-TGGGCCCGCAGATGCTTC-3' } \\
\text { 5'-AGGTTTGTTGGTCTGATAGCTC-3' }\end{array}$ & 58 & 498 & 28 & XM_524453 \\
\hline
\end{tabular}

Primers for PCR amplication. Specific primers were designed following the cDNA sequences of each gene in GenBank. The upstream primer is shown above the downstream primer in all cases. The expected fragments size upon amplification is given with optimal annealing temperature.

\section{Chondrogenic differentiation}

The chondrogenic medium contained the following components in addition to the control medium: $10 \mathrm{ng} / \mathrm{ml}$ transforming growth factor- $\beta 1$ (TGF- $\beta 1$ ) (R\&D Systems, Minneapolis, MN), $100 \mathrm{nM}$ dexamethasone (Sigma), $6.25 \mu \mathrm{g} / \mathrm{ml}$ insulin (Sigma), $50 \mathrm{nM}$ ascorbate-2phosphate (Sigma), $110 \mathrm{mg} / 1$ sodium pyruvate (Sigma). The medium was replaced every 3-4 days and chondrogenic differentiated PLA cells were passaged at 5-day intervals. Confluent monolayers were trypsinized $(0.2 \%$ trypsin; 5 minutes), washed, and reseeded into nutrient medium at a 1:3 ratio. This process was repeated until the chondrogenic PLA cells entered into senescence [12].

\section{Implantation of PLA cells and alginate gel mixture}

Accomplished 2-week induction to chondrogenesis, PLA cells were resuspended in $1.2 \%$ low-viscosity alginate in $0.15 \mathrm{M} \mathrm{NaCl}$ at a density of $1 \times 107 / \mathrm{ml}$ and then transferred to a $102 \mathrm{mM} \mathrm{CaCl}_{2}$ solution. After 15 minutes of polymerization at room temperature, the mixture was washed 3 times with normal saline, then 3 more times with the control medium. Twelve 6-week-old female BALB/C nude mice (West China Experimental Animal Center) were anesthetized using $30 \mathrm{mg} / \mathrm{kg}$ amylobarbitone sodium. Onemilliliter alginate gel mixed with induced and non-induced PLA cells or the acellular control gel was injected subcuta- 
neously on the dorsum of each mouse. The location of the each implant was randomized and recorded. At 4, 10, or 20 weeks postimplantation, mice were euthanized $(n=4$ for each time point). Implanted constructs were then carefully separated from surrounding fibrous capsule, washed in PBS, diced into several pieces, and immediately stored at liquid nitrogen or fixed for histological analysis.

\section{Histology and cellular morphology}

The retrieved specimens were fixed in $4 \%$ buffered paraformaldehyde overnight and embedded in paraffin. Cellular morphological features of PLA cells in monolayers or in $5 \mu \mathrm{m}$ sections were assessed with standard hematoxylin and eosin staining. Differentiated phenotype of cells in variant conditions was viewed and compared by phase-contrast microscopy.

\section{Immunohistochemical analysis}

Monolayer PLA cells grown on glass slides or $5 \mu \mathrm{m}$ sections of the cartilage tissue formed in nude mice were prepared for immunohistochemical analysis. Fixed cell slides or deparaffinized and rehydrated sections were incubated with $3 \%$ hydrogen peroxide in methanol for 30 minutes to inhibit endogenous peroxidase activity. After washed with PBS, they were blocked in $1 \%$ bovine serum albumin and 1.5\% normal goat serum at room temperature for 30 minutes. Slides were then incubated overnight at $4^{\circ} \mathrm{C}$ with goat polyclonal antibodies against aggrecan (Santa Cruz). Sequentially, slides were then incubated with secondary biotinylated antibodies and horseradish peroxide conjugated streptavidin to detect the primary antibodies. The peroxidase reaction was developed using 3,3'-diaminobenzidine tetrahydrochloride (DAB) as chromogens. After rinsing in distilled water, slides were dehydrated in ascending ethanol solutions, cleared in xylene, and covered with slips for microscopy.

\section{RNA isolation and reverse transcription- polymerase chain reaction}

Total RNA was extracted from all the specimens using the TRIzol Reagent (Life Technologies, Rockville, MD) according to the protocol. About $1 \mu \mathrm{g}$ of total RNA was reversed transcribed by murine leukemia virus reverse transcriptase (TaKaRa, Jap) and PCR amplification of target message RNA was performed by TaKaRa PCR kit (TaKaRa, Jap). PCR oligonucleotide primers, annealing temperature and optimized cycle number were listed in Table 1. Semiquantitative RT-PCR was performed at certain cycles for each specific gene because the amount of PCR products ought to be in lineage with cycle numbers. The products were electrophoresed on $1.5 \%$ agarose gels, stained with Ethidium Bromide and visualized with Quantity One software (BIO-RAD). Semiquantitative analysis of RT-PCR products was accomplished by computerized optical densitometry of the bands.

\section{Western blot analysis}

One hundred milligram of cartilage tissue were homogenized and lysed in $500 \mu \mathrm{l}$ of lysis buffer containing $50 \mathrm{mM}$ Tris $\cdot \mathrm{Cl}, 150 \mathrm{mM} \mathrm{NaCl}, 100 \mathrm{mg} / \mathrm{l}$ Phenylmethylsulfonyl fluoride, $1 \mathrm{mg} / 1$ Aprotinin, 1\% Tween $20,0.1 \%$ SDS. Five million cells from variant conditions were washed twice with PBS and also lysed in the above buffer. After $14,000 \mathrm{~g}$ centrifugation for $15 \mathrm{~min}$, the supernatant was collected, and protein concentrations were determined by the BCA assay (Pierce). Equal amounts of protein extracts were fractionated by $10 \%$ sodium dodecyl sulfate-polyacrylamide gels, and electrophoretically transferred to a nitrocellulose membrane (Bio-Rad). These nitrocelluloses were incubated with mouse monoclonal antibodies against type I collagen, type II collagen, type $\mathrm{X}$ collagen (NeoMarker), and housekeeping gene $\beta$-actin (Sigma). Immunoblotting was performed in the same way as mentioned in immunohistochemical analysis. The bands were scanned and evaluated by Quantity One software (BIO-RAD).

\section{Determination of GAG production}

Quantification of GAG production was performed by precipitation with Alcian Blue and DNA content assay was performed as internal control. In vitro cultured cells $\left(5 \times 10^{6}\right)$ or $50 \mathrm{mg}$ engineered cartilage from each group were homogenized and lysed in $500 \mu \mathrm{l}$ lysis buffer described in Western Blot protocol. The cell lysates were mixed with Alcian Blue to form GAG-dye complexes at a low $\mathrm{pH}$ condition ( $\mathrm{pH} 2.0$ ) in combination with nonionic detergent and high salt concentration. After washed by solution containing 40\% DMSO 

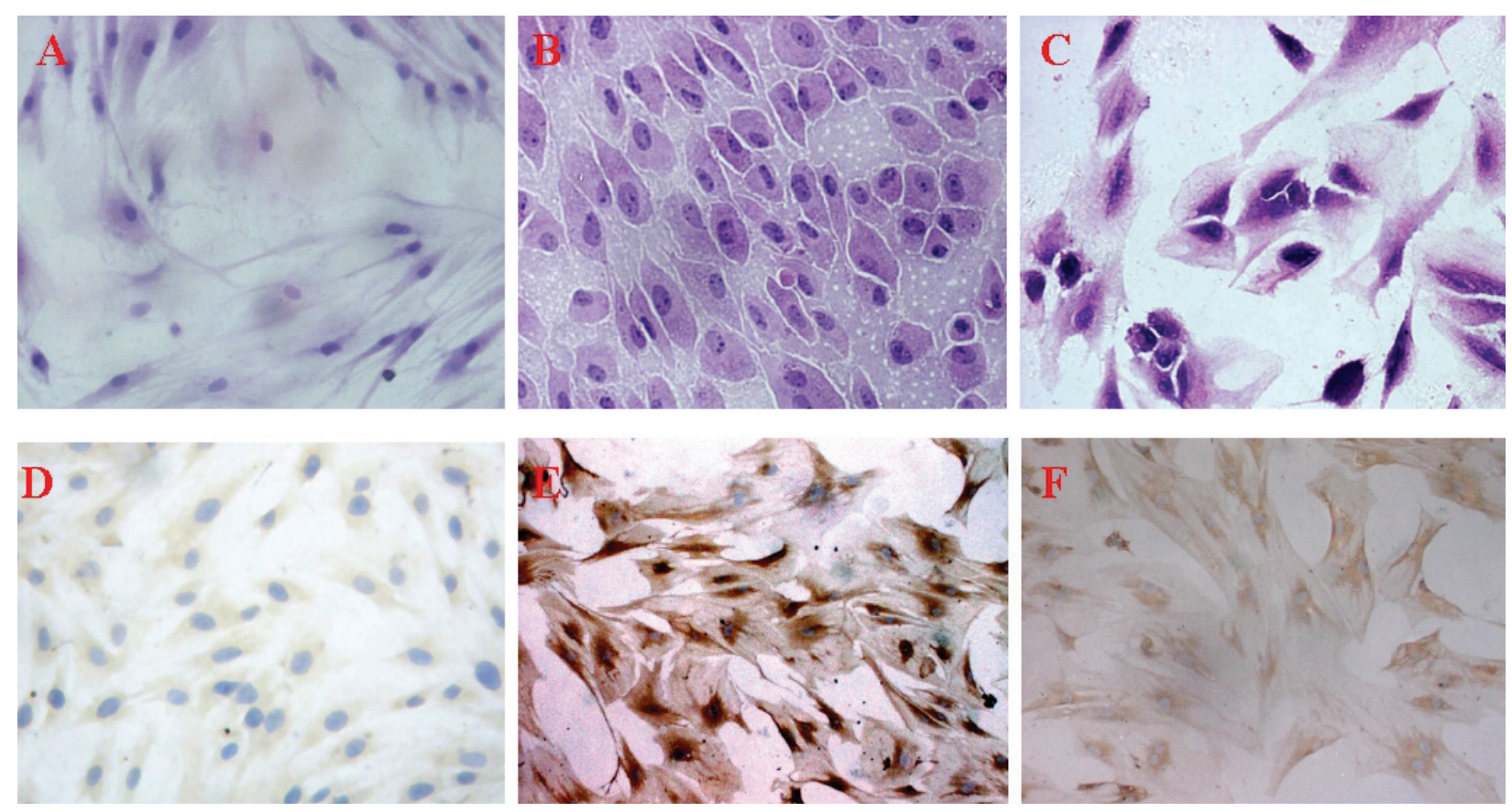

Fig. 1 HE staining (A, B and C) of monolayer PLA cells and immunohistochemical analysis of aggrecan (D, E and F) at different time points. A, D: PLA cells before chondrogenic induction. B, E: Two weeks after chondrogenic induction. C, F: Ten weeks after chondrogenic induction. (Original magnification of all images 400×)

and $0.05 \mathrm{M} \mathrm{MgCl}_{2}$, the complexes were dissolved in dissociation mixture $(4.0 \mathrm{M}$ guanidine- $\mathrm{HCl}$ and $33 \%$ propanol) and transferred to a 96-well plate. The absorbance is measured at $600 \mathrm{~nm}$ to determine the level of GAG production in each sample.

\section{Statistical analysis}

We performed 9 independent sets of the experiments from 9 donors, and each experiment was run at least 3 times. Data were expressed as means \pm SD and analyzed by a paired analysis of variance or One-Way ANOVA. P values were described in tables or figures and $\mathrm{P}<0.05$ was considered statistically significant.

\section{Results}

\section{Phenotypic alteration of chondrogenic PLA cells in vitro}

When isolated and primarily cultured as monolayers, PLA cells indicated cellular constitution of elongated spindle-shape and displayed no obvious pericellular matrix and immunostaining of aggrecan before chondrogenic induction (Fig. 1A, 1D). After placed into chondrogenic medium for 7 days, the PLA cells exhibited changes in cell structure, modulating from fibroblastic appearance to a polygonal shape. Two weeks after induction, we observed the cells in monolayer at high density tended to form spheroids and had large nuclei with multiple nucleoli similar to the normal chondrocytes. Hematoxylin and eosin analysis showed that they seemed to be surrounded by a fairly uniform proteoglycan-rich matrix that is denser adjacent to the cell clusters (Fig. 1B). With immunostaining, they showed highly positive of aggrecan (Fig. 1E). As the chondrogenic cells were passaged in vitro, most of them stopped division at late stage about 10 weeks after initial differentiation and adopted a giant morphology with numerous vacuoles (Fig. 1C). The other cell population no longer produced cartilaginous matrix actively, but showed phenotype like fibroblasts. The cells began to lose the positive staining of aggrecan (Fig. 1F). 

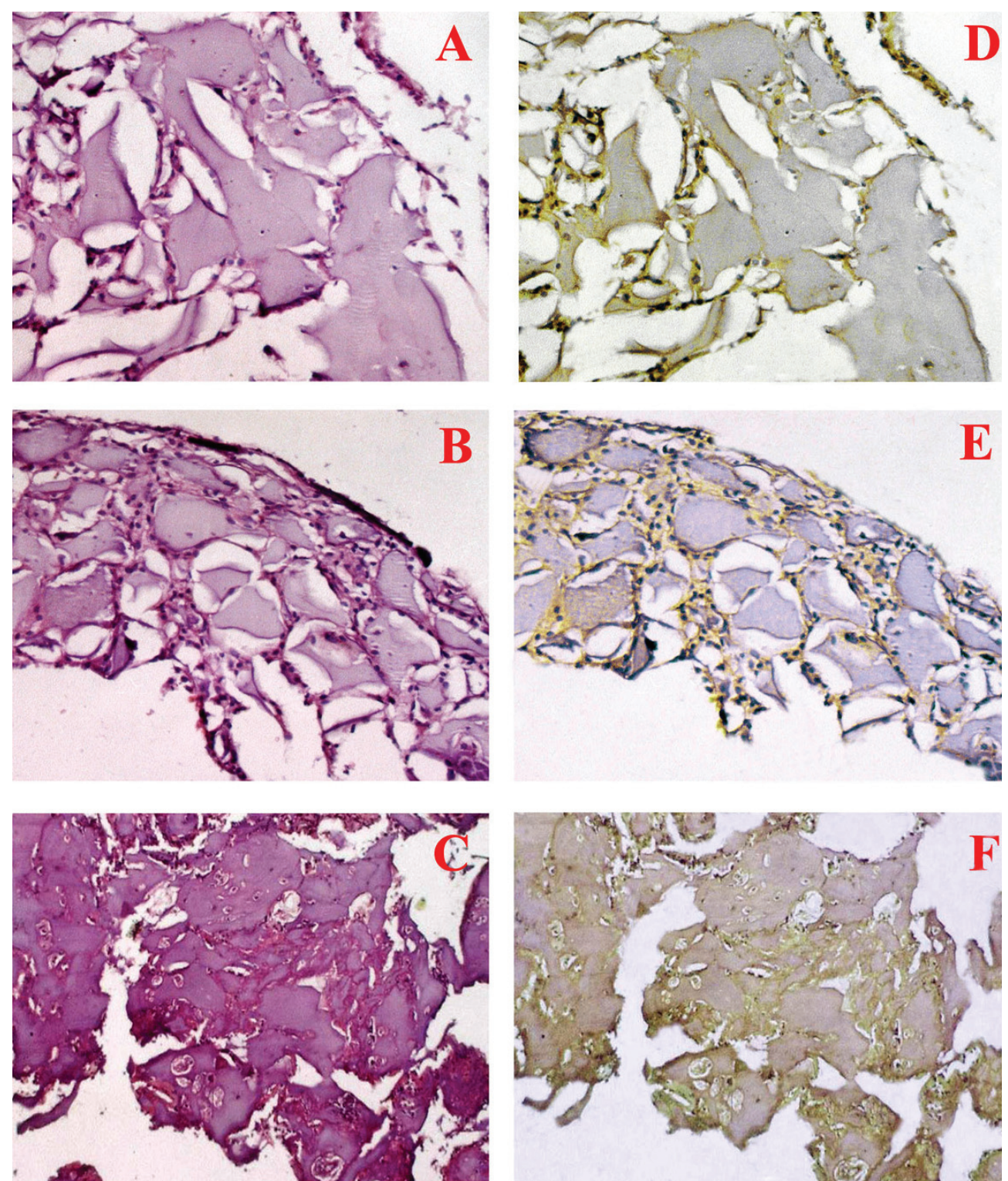
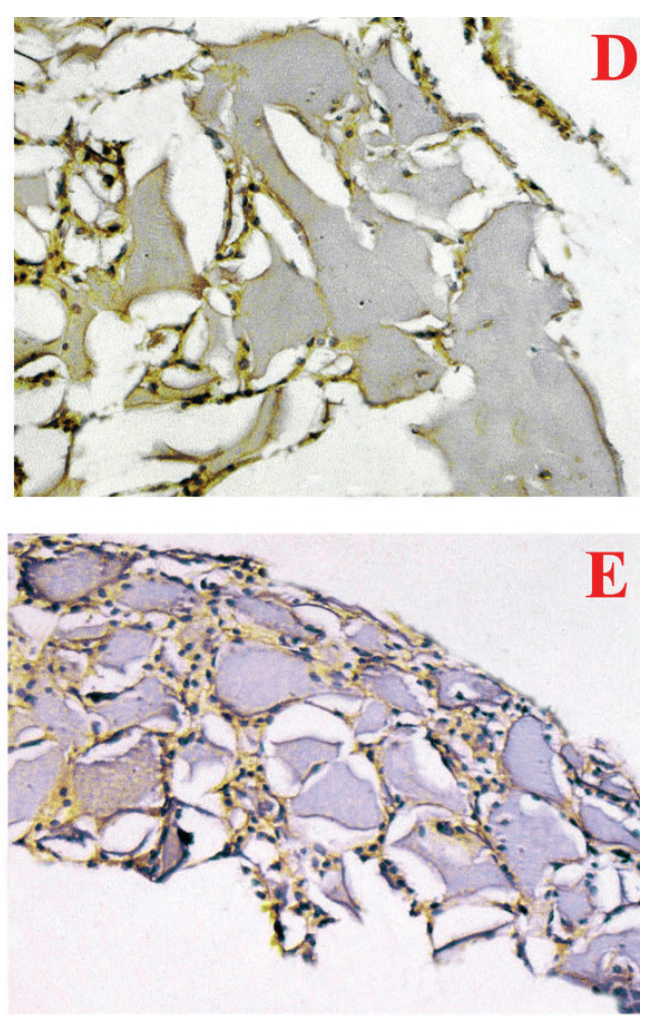

E cal analysis of aggrecan $(\mathrm{D}, \mathrm{E}$ and $\mathrm{F})$ at different time point. A, D: Four weeks after implantation (Original magnification of images $100 \times$ ). B, E: Ten weeks after i m p la n t a t i o n (Original magnification of images $40 \times$ ). C, F: Twenty weeks after implantation. (Original magnification of images $40 \times$ )

\section{Macromorphology of engineered cartilage in vivo}

The alginate gel mixed with chondrogenic PLA cells injected into BALB/C nude mice subcutaneously formed engineered chondroid constructs in 4 weeks (Fig. 2A). The size of cartilaginous constructs in vivo became smaller with time increasing, and they reduced to $50-60 \%$ of original size at the time point of 20 weeks. Gross observation of the tissue-engineered cartilages indicated that they were capsuled by connective tissues and not attached to the surrounding tissues tightly. HE staining showed that there were substantial amounts of cartilaginous matrix containing cells encased in chondrocytic lacunae initially at the time point of 10 weeks (Fig. 2B). There was accumulation of ECM in the engineered cartilage during the period of 20 weeks (Fig. 2C), which made it opaque and malleable. Finally, they exhibited histological features of genuine cartilage matrix with the context of a typical cartilaginous structure. The control injections of pure alginate gel or non-induced cells disappeared in 4 weeks and nothing were received in the end.

\section{Components of ECM produced by PLA cells during chondrogenic differentiation in vitro}

The cell morphology of induced PLA cells was evident that they obtained the differentiation pheno- 

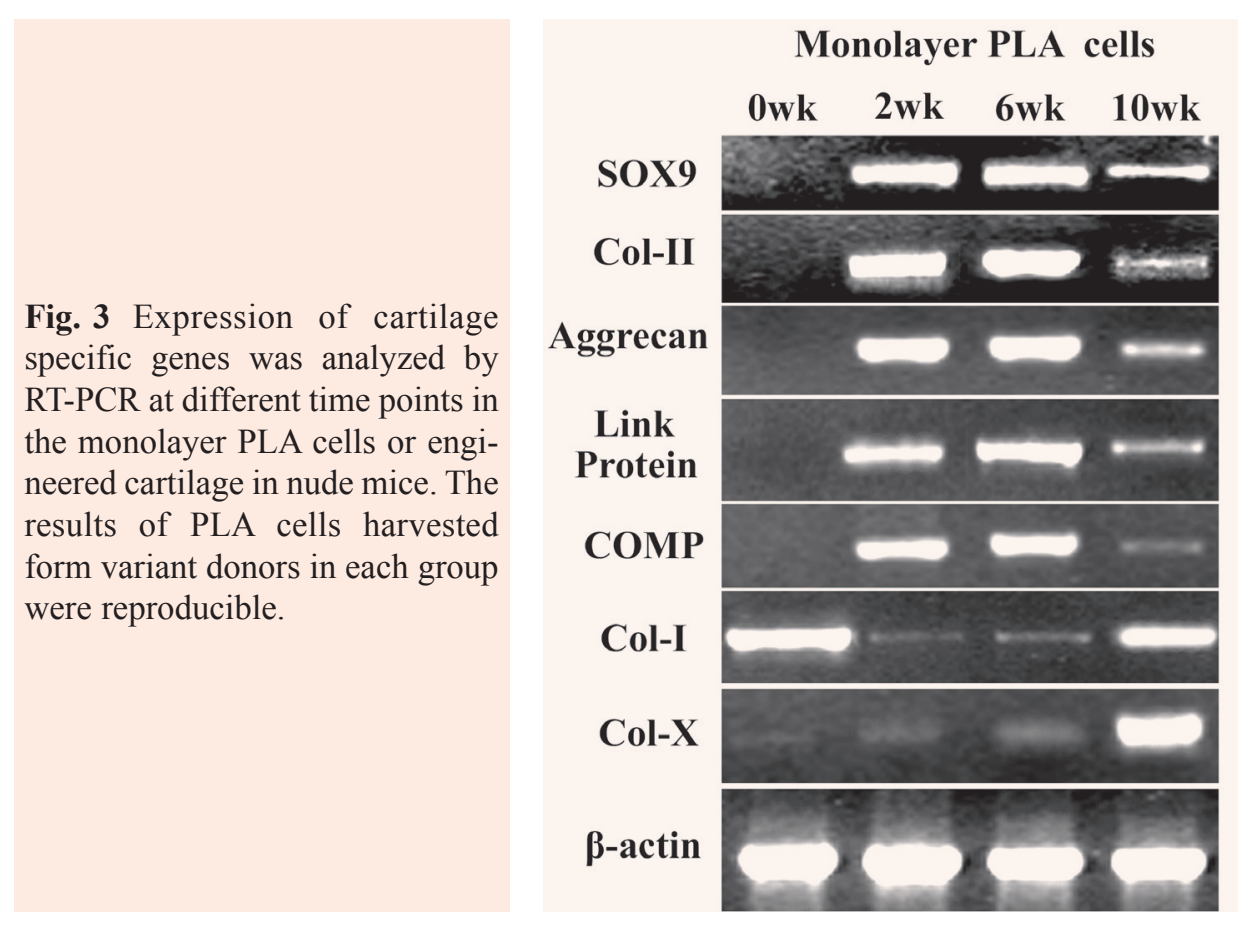

\section{Engineered Cartilage}

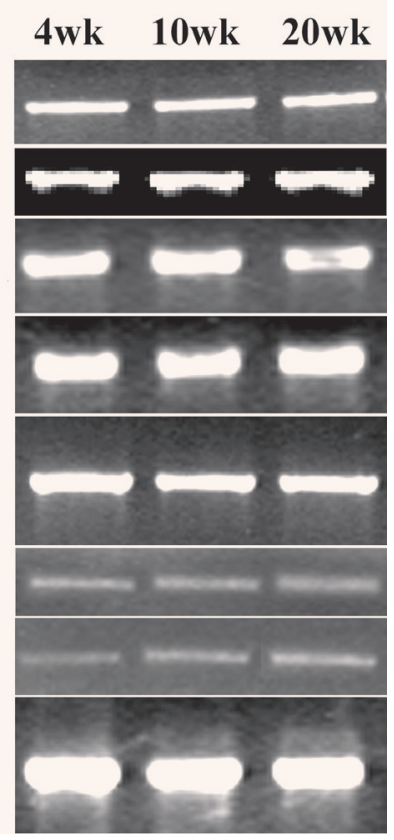

type as chondrogenic lineages. In order to further verify the expression of marker genes of chondrocytes, molecular biological and immunocytochemical analysis were performed. The expression of the collagen II (Col2 $\alpha 1)$ and SOX9 is an early and practically unique marker of chondrocyte differentiation [12-16]. RT-PCR analysis of mRNA encoding type II collagen and SOX9 showed that high level expression of these genes in PLA cells cultured in chondrogenic medium for 2 weeks. The chondrogenesis of PLA cells was supported by presence of some other important components of cartilaginous ECM, such as cartilage oligomeric protein (COMP) and aggrecan [17-21]. But these genes were not observed in the cells incubated in the control medium (labeled as $0 \mathrm{wk}$ in inductive medium in Fig. 3). There was a trend to decrease in expression of type I collagen after induction (Fig. 3). Western blot results correlated with these findings and indicated active production of specific matrix for cartilaginous content at early stage during differentiation (Fig. 4). Numerous GAG chains are covalently attached to the aggrecan core protein, including chondroitin sulfate and keratin sulfate $[22,23]$. After 2 weeks of induction, GAG synthesis in PLA cells was significantly switched to 2.6fold of controls (Fig. 5A) accompanied by dramatic increase of aggrecan expression at mRNA and protein level (Fig. 3).
The chondrogenic PLA cells cultured in monolayer were stable with no sign of hypertrophy for up to 6-8 weeks in chondrogenic medium. The changes in morphological features were observed at the time point of 10 weeks after induction, paralleling with significant decreases of cartilaginous specific collagen, COMP, and aggrecan production to about $40-60 \%$ (Fig. 3 and Fig. 4). It was found that in latestage prehypertrophic PLA cells, the content of GAG was only about $35 \%$ compared to that in earlystage chondrogenic ones (Fig. 5A). As shown in Fig. $1 \mathrm{~F}$, cultured 10 weeks in monolayers after induction, PLA cells lost most of aggrecan in ECM components and stained weakly in immunohistochemical analysis. Instead, they began to produce type I collagen with 4-fold increase and high level of type X collagen-the specific marker for prehypertrophy. But as a transcriptional factor, the level of SOX9 retained about $70 \%$ of the early ones (Fig. 3), not like the great changes in ECM molecules, which was probably present in the period of prehypertrophy or regulated by other mechanisms [24, 25].

\section{Components of ECM in the engineered cartilage}

For in vivo evaluation of cartilage matrix molecules produced by chondrogenic PLA cells, induced cells 


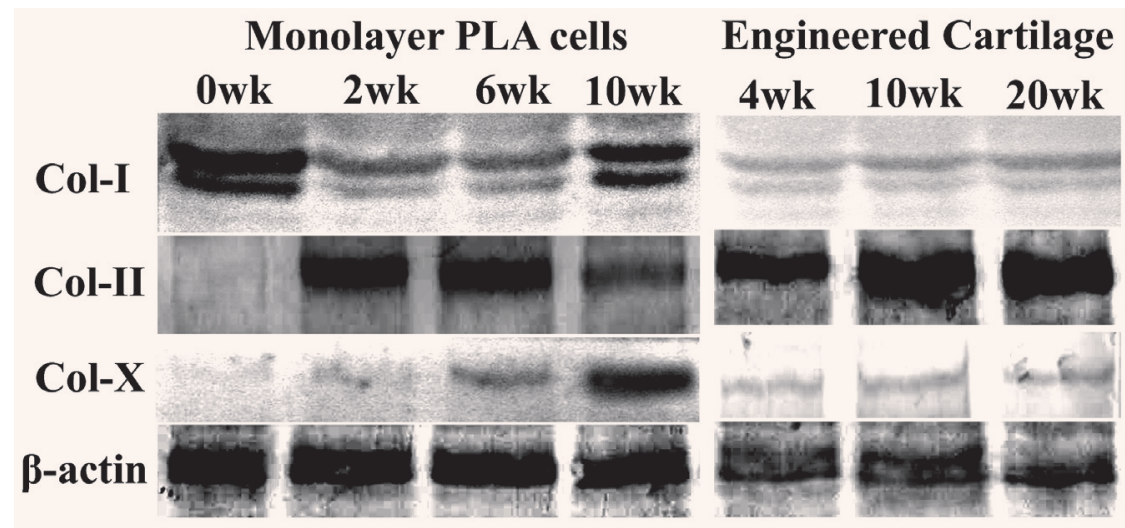

Fig. 4 Expression of collagen type I, II and X was analyzed by Western Blot at different time points in the monolayer PLA cells or engineered cartilage in nude mice. The results of PLA cells harvested form variant donors in each group were reproducible.

seeded alginate gel was implanted in immunotolerant mice subcutaneously [26]. As measured by RTPCR, the mRNA encoding specific ECM molecules maintained moderate level in the formed cartilage in comparison with the early-stage cells cultured as
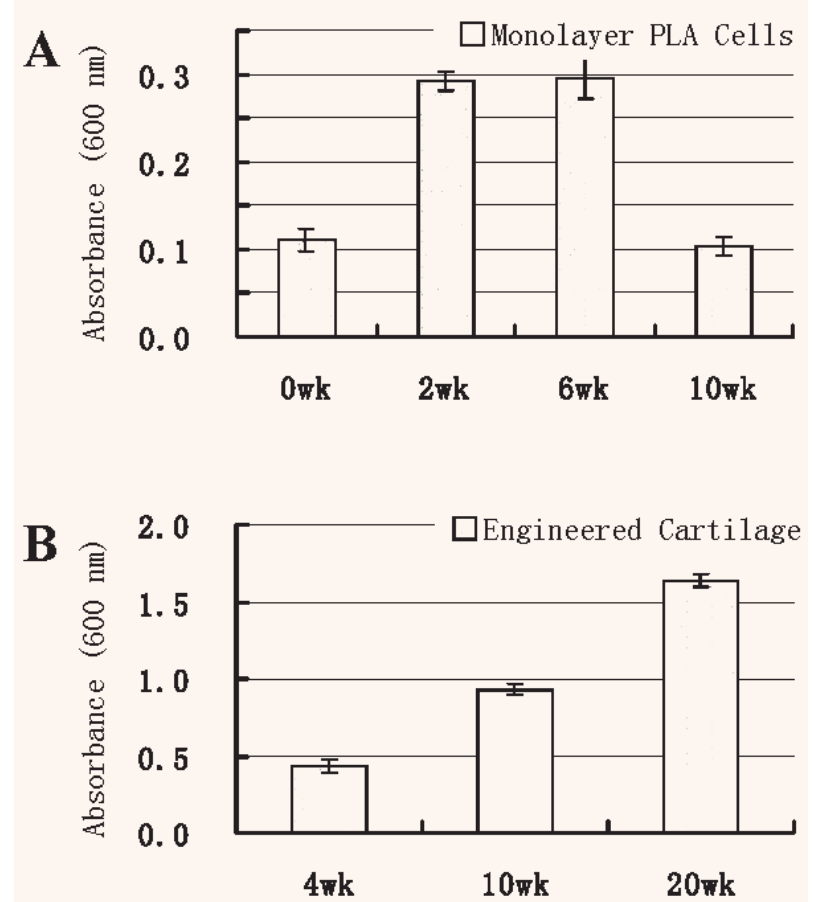

Fig. 5 Production of GAG in the monolayer PLA cells (A) or engineered cartilage in nude mice (B) was determined by the absorbance at $600 \mathrm{~nm}$ of GAG-dye dilution in each group at different time points $(n=6)$. A: The synthesis of GAG in the chondrogenic PLA cells 2 and 6 weeks after induction were significant more than those before induction or 10 weeks after induction. B: The synthesis of GAG in the engineered cartilage in nude mice stepwise increased significantly. monolayers. However, there was no great alteration in the expression of these genes during 20 weeks in vivo, which was far different from the monolayer cells (Fig. 3). In immunohistochemical staining, the aggrecan protein was always strongly positive in the engineered tissue at variant time point till this study finished (Fig. 2D, E, F). There was significant accumulation of ECM components in pericellular matrix with time increasing detected by Western Blot (Fig. 4) and the content of GAG had the same trend as a result of long period production (Fig. 5B).

On the other hand, the proportion of type I collagen decreased in ECM during cartilage formation in vivo and kept lower since then, which was confirmed by the weak density of bands in RT-PCR and Western Blot analysis. The PLA cells in the engineered construct still showed a weakly increasing trend in the expression of type $\mathrm{X}$ collagen. Nevertheless, the pattern of type $X$ collagen in ECM remained stably low and showed little differences in the retrieved specimens at 10 weeks or 20 weeks. It was suggested that the PLA cells induced to chondrogenic lineages could form engineered cartilage, maintained the stable phenotype and had no sign of hypertrophy in 20 weeks in vivo.

\section{Discussion}

Nowadays, it has been found that the cell population in adipose tissue, called processed lipoaspirate (PLA) cells, can be isolated easily in large numbers and exhibits stable growth and proliferation kinetics in culture $[12,27]$. Moreover, PLA cells can retain their chondrogenic differentiation capacity in a relatively long time when treated with established lin- 
eage-specific factors in vitro [12]. Based on this, adipose tissue may represent a source of stem cells that could have far-reaching effects on the fields associated with clinical application of cartilage engineering. But there have been no detailed reports on the molecular and cellular characterization of PLA cells during chondrogenic differentiation in vitro and cartilage formation in vivo. In this study, we used PLA cells derived from human adipose tissue, in vitro expansion as monolayers under chondrogenic conditions, or implantation in vivo in conjunction with an alginate carrier, to investigate and compare their processes of chondrogenesis, maturity and hypertrophy.

It was confirmed that the chondrogenesis of PLA cells both in vitro and in vivo in the molecular and immunohistochemical analysis. Even if the PLA cells cultured as monolayers under high density, they expressed cartilaginous marker genes in 14 days after incubated with chondrogenic medium. However, it's well known that primary mammalian cells cultured in vitro have a finite replicative life span and eventually enter a state of senescence [28]. Due to entry into the differentiated state, there was great difference in proliferation potential between the inductive and non-inductive PLA cells in vitro. It was observed that the chondrogenic PLA cells decreased in cell number at confluence, reduced cell replication rate, and increased cell volume with the culture time increasing just as the genuine chondrocytes $[29,30]$. Previous studies have suggested that during a serial of passaging in vitro, primary connective tissue cell types, especially chondrocytes, don't only show decline in cell viability and increase in cell apoptosis, but also lose their phenotype to be dedifferentiated. Maintenance of the chondrocyte phenotype in vitro requires the cells to remain in a three-dimensional configuration $[31,32]$. The same phenomena also happened in the passaged chondrogenic PLA cells with the exhibition of alteration in pericellular ECM components. This would suggest that PLA cells should be passaged without induction to obtain sufficient cells for application lest the differentiated PLA cells would lose their potential of division and normal function rapidly in vitro as passaging in monolayer conditions.

The induction of chondrogenesis in PLA cells cultured in vitro required supplementation with specific soluble mediators. Particularly, the growth factor TGF- $\beta 1$ plays a key role in the regulation of cel- lular proliferation, differentiation, and cartilage formation [33]. Indeed, as multifunctional growth factors, TGF- $\beta 1$ could exhibit differential effects depending on the differentiation stage of the target cells. It can also inhibit hypertrophic differentiation of chondrocyte and is required for maintaining articular cartilage [34]. In this study, TGF- $\beta 1$ in combination with other media supplements caused the PLA cells to produce cartilage markers, in agreement to mesenchymal stem cells derived from bone marrow $[35,36]$. The differentiated lineages were always cultured in the chondrogenic medium containing TGF- $\beta 1$; however, they still had phenotypic alteration in 10 weeks cultured as monolayer.

With use of alginate scaffold for in vivo implantation, it was to determine how stable the engineered tissue was, and whether it would turn to hypertrophic cartilage. Although differentiated PLA cells are not actual chondrocytes, the chondrogenic nature of these cells in the cartilaginous tissue formed in vivo was supported by the following characteristics. HE morphological features of the tissue sections showed a perichondral border of cells surrounding a hypocellular chondrogenic core in threedimensional alginate system. Our findings demonstrated that synthesis of aggrecan, type II collagen, cartilage oligomeric protein and SOX9 in engineered cartilage in vivo stably maintained at moderate levels, which was consistent with the results of previous studies that the ECM turnover in cartilage was more slowly than that of in vitro cells [37]. Connective tissue such as cartilage contains a relatively sparse population of cells within an ECM rich in collagen and proteoglycan. The cells are entrapped in a collagenous network and responsible for the synthesis, maintenance, and gradual turnover of the ECM. At the time point of 20 weeks, there were no obvious increments of type I collagen or type X collagen, which were the initial events of hypertrophy and matrix calcification [38]. From these results, we thought that the influence of spatial environments is probably as important as, if not more important than, that of growth factors to the stability of phenotype in chondrogenic PLA cells.

New techniques involving implantation of cells and tissue-engineered constructs are being developed to improve musculoskeletal tissue repair [39, 40]. From a tissue-engineering point of view, PLA cells led us to speculate that a population of multipotent stem cells, comparable with MSCs, can be 
applied in broad fields clinically. Based on our data, it is proposed that PLA cells own relatively high proliferative potential before specific induction and lose cellular viability soon after induction. We should obtain adequate number of cells for construct by multiple cell divisions firstly and then induce them to lineages in appropriate conditions. If allied with other biological means, for example, utilizing electroporation, chemical reagents including calcium phosphate precipitation and lipofection to transfected plasmids or viral vectors carrying genes encoding growth factors into PLA cells, the engineered tissue can be formed even more efficiently $[41,42]$. It may lead to a better outcome that genetically modified PLA cells seeded in constructs are implanted in the defects immediately, which facilitates retention of high level expression locally and adaptation to the adjacent tissues.

PLA cells offer an opportunity for us to establish implantation schemes to heal tissue defects. Further work lies ahead to optimize the culture and engineering procedures. Necessarily, we should determine the ideal expansion conditions in vitro, the composition and structure of the ideal carrier, the numbers of cells that are required for a defined volume of cartilage, and the most suitable transfection approach or multiplicities of infection for PLA cells.

\section{Acknowledgements}

We thank Shengwei Li for excellent technical support and Lei Liu help with manuscript preparation. This work was supported by generous grant from the Chinese National Natural Science Foundation (30200318), the Special Project of National Grand Fundamental Research Program of China (2002CCC00700) and Teaching \& Research Award for Outstanding Young Teachers in Higher Education Institutions of PR China (2003682).

\section{References}

1. Homminga GN, Bulstra SK, Bouwmeester PS, van der Linden AJ. Perichondral grafting for cartilage lesions of the knee. J Bone Joint Surg Br. 1990; 72: 1003-7.

2. Hangody L, Kish G, Karpati Z, Udvarhelyi I, Szigeti I, Bely M. Mosaicplasty for the treatment of articular carti- lage defects: Application in clinical practice. Orthopedics 1998; 21: 751-6.

3. Fortier LA, Nixon AJ, Williams J, Cable CS. Isolation and chondrocytic differentiation of equine bone marrow-derived mesenchymal stem cells. Am J Vet Res. 1998; 59: 1182-7.

4. Gronthos S, Zannettino AC, Hay SJ, Shi S, Graves SE, Kortesidis A, Simmons PJ. Molecular and cellular characterisation of highly purified stromal stem cells derived from human bone marrow. J Cell Sci. 2003; 116: 1827-35.

5. Reyes M, Lund T, Lenvik T, Aguiar D, Koodie L, Verfaillie CM. Purification and ex vivo expansion of postnatal human marrow mesodermal progenitor cells. Blood 2001; 98: 2615-25.

6. Jaiswal N, Haynesworth SE, Caplan AI, Bruder SP. Osteogenic differentiation of purified, culture expanded human mesenchymal stem cells in vitro. J Cell Biochem. 1997; 64: 295-312.

7. Zuk PA, Zhu M, Mizuno H, Huang J, Futrell JW, Katz AJ, Benhaim P, Lorenz HP, Hedrick MH. Multilineage cells from human adipose tissue: Implications for cellbased therapies. Tissue Eng. 2001; 7: 211-28.

8. Saladin R, Fajas L, Dana S, Halvorsen YD, Auwerx J, Briggs M. Differential regulation of peroxisome proliferator activated receptor gammal (PPAR- $\gamma 1$ ) and PPAR $\gamma 2$ messenger RNA expression in the early stages of adipogenesis. Cell Growth Differ. 1999; 10: 43-8.

9. Halvorsen YD, Bond A, Sen A, Franklin DM, LeaCurrie YR, Sujkowski D, Ellis PN, Wilkison WO, Gimble JM. Thiazolidinediones and glucocorticoids synergistically induce differentiation of human adipose tissue stromal cells: Biochemical, cellular, and molecular analysis. Metab Clin Exp. 2001; 50: 407-13.

10. Huang JI, Zuk PA, Jones NF, Zhu M, Lorenz HP, Hedrick MH, Benhaim P. Chondrogenic potential of multipotential cells from human adipose tissue. Plast Reconstr Surg. 2004; 113: 585-94.

11. Wickham MQ, Erickson GR, Gimble JM, Vail TP, Guilak F. Multipotent stromal cells derived from the infrapatellar fat pad of the knee. Clin Orthop. 2003; 412: 196-212.

12. Lin Y, Tian W, Chen X, Yan Z, Li Z, Qiao J, Liu L, Tang W, Zheng $\mathbf{X}$. Expression of exogenous or endogenous green fluorescent protein in adipose tissue-derived stromal cells during chondrogenic differentiation. Mol Cell Biochem. 2005; 277:181-90.

13. Zuk PA, Zhu M, Ashjian P, De Ugarte DA, Huang JI, Mizuno H, Alfonso ZC, Fraser JK, Benhaim P, Hedrick MH. Human adipose tissue is a source of multipotent stem cells. Mol Biol Cell. 2002; 13: 4279-95.

14. Sive JI, Baird P, Jeziorsk M, Watkins A, Hoyland JA, Freemont AJ. Expression of chondrocyte markers by cells of normal and degenerate intervertebral discs. Mol Pathol. 2002; 55: 91-7.

15. Sekiya I, Vuoristo JT, Larson BL, Prockop DJ. In vitro cartilage formation by human adult stem cells from bone marrow stroma defines the sequence of cellular and molecular events during chondrogenesis. Proc Natl Acad Sci USA. 2002; 99: 4397-402.

16. Lefebvre V, Huang W, Harley VR, Goodfellow PN, de Crombrugghe B. SOX9 is a potent activator of the chon- 
drocyte-specific enhancer of the pro $\alpha 1$ (II) collagen gene. Mol Cell Biol. 1997; 17: 2336-46.

17. Tanaka H, Murphy CL, Murphy C, Kimura M, Kawai S, Polak JM. Chondrogenic differentiation of murine embryonic stem cells: effects of culture conditions and dexamethasone. J Cell Biochem. 2004; 93: 454-62.

18. Schwartz NB, Pirok EW $3^{\text {rd }}$, Mensch JR Jr, Domowicz MS. Domain organization, genomic structure, evolution, and regulation of expression of the aggrecan gene family. Prog Nucleic Acid Res Mol Biol. 1999; 62: 177-225.

19. Bayliss MT, Howat S, Davidson C, Dudhia J. The organization of aggrecan in human articular cartilage. Evidence for age-related changes in the rate of aggregation of newly synthesized molecules. J Biol Chem. 2000; 275: 6321-7.

20. Skioldebrand E, Heinegard D, Eloranta ML, Nilsson G, Dudhia J, Sandgren B, Ekman S. Enhanced concentration of COMP (cartilage oligomeric matrix protein) in osteochondral fractures from racing Thoroughbreds. $J$ Orthop Res. 2005; 23: 156-63.

21. Crnkic M, Mansson B, Larsson L, Geborek P, Heinegard D, Saxne T. Serum cartilage oligomeric matrix protein (COMP) decreases in rheumatoid arthritis patients treated with infliximab or etanercept. Arthritis Res Ther. 2003; 5: R181-5.

22. Watanabe H, Yamada Y, Kimata K. Roles of aggrecan, a large chondroitin sulfate proteoglycan, in cartilage structure and function. J Biochem. (Tokyo) 1998; 124: 687-93.

23. Knudson CB, Knudson W. Cartilage proteoglycans. Semin Cell Dev Biol. 2001; 12: 69-78.

24. Tchetina E, Mwale F, Poole AR. Distinct phases of coordinated early and late gene expression in growth plate chondrocytes in relationship to cell proliferation, matrix assembly, remodeling, and cell differentiation. $J$ Bone Miner Res. 2003; 18: 844-51.

25. Goldring MB. Human chondrocyte cultures as models of cartilage-specific gene regulation. Methods Mol Med. 2004; 107: 69-96.

26. Paige KT, Cima LG, Yaremchuk MJ, Schloo BL, Vacanti JP, Vacanti CA. De novo cartilage generation using calcium alginate-chondrocyte constructs. Plastic Reconstruct Surg. 1996; 97: 168-80.

27. Dragoo JL, Choi JY, Lieberman JR, Huang J, Zuk PA, Zhang J, Hedrick MH, Benhaim P. Bone induction by BMP-2 transduced stem cells derived from human fat. $J$ Orthop Res. 2003; 21: 622-9.

28. Martin JA, Mitchell CJ, Klingelhutz AJ, Buckwalter JA. Effects of telomerase and viral oncogene expression on the in vitro growth of human chondrocytes. J Gerontol A Biol Sci Med Sci. 2002; 57: B48-53.

29. Barbero A, Grogan S, Schafer D, Heberer M, MainilVarlet P, Martin I. Age related changes in human articular chondrocyte yield, proliferation and post-expansion chondrogenic capacity. Osteoarthritis Cartilage 2004; 12: 476-84.

30. Ariga K, Miyamoto S, Nakase T, Okuda S, Meng W, Yonenobu K, Yoshikawa H. The relationship between apoptosis of endplate chondrocytes and aging and degeneration of the intervertebral disc. Spine 2001; 26: 2414-20.

31. Benya PD, Shaffer JD. Dedifferentiated chondrocytes reexpress the differentiated collagen phenotype when cultured in agarose gels. Cell 1982; 30: 215-24.

32. Binette F, McQuaid DP, Haudenschild DR, Yaeger PC, McPherson JM, Tubo R. Expression of a stable articular cartilage phenotype without evidence of hypertrophy by adult human articular chondrocytes in vitro. J Orthopaed Res. 1998; 16: 207-16.

33. Miyazaki Y, Tsukazaki T, Hirota Y, Yonekura A, Osaki M, Shindo H, Yamashita S. Dexamethasone inhibition of TGF $\beta$-induced cell growth and type II collagen mRNA expression through ERK-integrated AP-1 activity in cultured rat articular chondrocytes. Osteoarthritis Cartilage 2000; 8: 378-85.

34. Joyce ME, Roberts AB, Sporn MB, Bolander ME. Transforming growth factor- $\beta$ and the initiation of chondrogenesis and osteogenesis in the rat femur. J Cell Biol. 1990; 110: 2195-207.

35. Ponticiello MS, Schinagl RM, Kadiyala S, Barry FP. Gelatin-based resorbable sponge as a carrier matrix for human mesenchymal stem cells in cartilage regeneration therapy. J Biomed Mater Res. 2000; 52: 246-55.

36. Kramer J, Hegert C, Guan K, Wobus AM, Muller PK, Rohwedel J. Embryonic stem cell-derived chondrogenic differentiation in vitro: activation by BMP-2 and BMP-4. Mech Dev 2000; 92: 193-205.

37. Stockwell RA, Sprinz R. Glycosaminoglycan content and cell density of rabbit articular cartilage in experimental lipoarthrosis. J Anat. 1981; 133: 309-15.

38. Goessler UR, Bugert P, Bieback K, Baisch A, Sadick H, Verse T, Kluter H, Hormann K, Riedel F. Expression of collagen and fiber-associated proteins in human septal cartilage during in vitro dedifferentiation. Int J Mol Med. 2004; 14: 1015-22.

39. Korbling M, Estrov Z, Champlin R. Adult stem cells and tissue repair. Bone Marrow Transplant. 2003; 32 Suppl 1: S23-4.

40. Glowacki J. Engineered cartilage, bone, joints, and menisci. Potential for temporomandibular joint reconstruction. Cells Tissues Organs 2001; 169: 302-8.

41. Wu D, Razzano P, Grande DA. Gene therapy and tissue engineering in repair of the musculoskeletal system. J Cell Biochem. 2003; 88: 467-81.

42. Trippel SB, Ghivizzani SC, Nixon AJ. Gene-based approaches for the repair of articular cartilage. Gene Ther. 2004; 11: 351-9. 